\title{
Region-Specific, Life-Threatening Diseases among International Travelers from Israel, 2004-2015
}

\section{Chen Avni, Shmuel Stienlauf, Eyal Meltzer, Yechezkel Sidi, Eli Schwartz, Eyal Leshem}

We characterized posttravel hospitalizations of citizens returning to Israel by summarizing the returning traveler hospitalization dataset of the national referral Center for Travel Medicine and Tropical Diseases at Sheba Medical Center in Israel. Of 722 hospitalizations, 181 (25\%) infections were life-threatening; most would have been preventable by chemoprophylaxis and pretravel vaccination.

$\mathrm{I}^{\mathrm{I}}$ nternational travel, particularly to tropical regions and low-income countries, may be associated with the risk for acute illness and hospitalization (1). The Center for Travel Medicine and Tropical Diseases at Sheba Medical Center (SMC; Tel Hashomer, Israel) is the national referral center for travel-associated illness in Israel. We characterized posttravel hospitalizations of citizens returning to Israel by summarizing the SMC returning traveler hospitalization dataset.

\section{The Study}

We investigated all international travel-associated hospitalizations of citizens of Israel at SMC during 2004-2015. We excluded case-patients for whom the time interval between return from travel and symptom onset exceeded the known incubation period for the cause of hospitalization. When identified illness after travel leading to hospitalization was nonendemic to Israel and caused symptoms after a long incubation (e.g., leishmaniasis, schistosomiasis), patients were included regardless of the time interval since return. We defined nonspecified febrile illness as a febrile illness with an undetermined cause (2). We excluded hospitalized persons who had unspecified febrile illness when the interval between return from travel and disease onset exceeded 2 weeks, because of the lower certainty of association between travel and illness. We defined acute and potentially life-threatening tropical diseases as infectious diseases largely confined to tropical and subtropical areas

Author affiliations: The Center for Travel Medicine and Tropical Diseases, The Chaim Sheba Medical Center, Tel Hashomer, Israel; Sackler School of Medicine, Tel Aviv University, Tel Aviv, Israel

DOI: https://doi.org/10.3201/eid2404.171542 of the world that had an incubation period of $>4$ weeks and an estimated risk for death $>5 \%$ within 4 weeks after symptom onset if left untreated (3).

We determined the country of disease acquisition by a history of travel to a single country or exposure to a single country during the incubation period for the cause of hospitalization. To put the number of hospitalizations for illness acquired in each destination country in context of the estimated number of Israelis traveling to that country, we extracted the number of Israeli citizen entries by country from the United Nations World Tourism Organization dataset (4). We compared continuous variables by using the Student $t$-test and compared categorical variables by using the $\chi^{2}$ test. Statistical significance was set at $\mathrm{p}<0.05$. The SMC Institutional Review Board approved this study.

During 2004-2015, a total of 722 travelers returning to Israel were hospitalized (Table 1; online Technical Appendix Table 1, https://wwwnc.cdc.gov/EID/article/24/4/171542-Techapp1.pdf). The median patient age was 33 years (interquartile range 26-50 years); 530 (73\%) were male. By continent, 330 (46\%) patients had traveled to Asia; 267 (37\%) to Africa; and 73 (10\%) to South America, Central America, and the Caribbean. The travel destination countries from which the highest number of travelers were hospitalized were India (116 [16\%]), Thailand (106 [15\%]), and Ethiopia (48 [7\%]). In relative terms, several countries, mostly in Africa, had a high number of hospitalizations respective to the estimated number of entries by Israeli citizens (Figure; online Technical Appendix Table 2).

Overall, the most common causes of hospitalization were malaria (145 [20\%]), dengue (74 [10\%]), and enteric fever (59 [8\%]). Among 145 hospitalized malaria patients, $86(59 \%)$ tested positive for Plasmodium falciparum. For Asia, the most common causes of admission were dengue fever, enteric fever, and unspecified febrile illnesses; for Africa, the most common were malaria, unspecified febrile illnesses, and acute schistosomiasis; and for South America, Central America, and the Caribbean, the most common were dengue fever and leptospirosis.

Patients hospitalized for $P$. falciparum malaria $(\mathrm{n}=86)$ were older than those positive for $P$. $\operatorname{vivax}(\mathrm{n}=36)(43 \pm 14$ y vs. $34 \pm 12 \mathrm{y} ; \mathrm{p}<0.01)$ and were more likely to be business travelers (39 [45\%] 
Preventable Diseases among Travelers from Israel

Table 1. Characteristics of travel-associated hospitalizations of citizens of Israel at Sheba Medical Center, Israel, 2004-2015*

\begin{tabular}{|c|c|c|c|c|c|c|c|}
\hline Category & $\begin{array}{c}\text { Africa, } \\
\mathrm{n}=267\end{array}$ & $\begin{array}{c}\text { Asia, } \\
\mathrm{n}=330\end{array}$ & $\begin{array}{c}\text { South } \\
\text { America, } \\
\mathrm{n}=43\end{array}$ & $\begin{array}{c}\text { Central } \\
\text { America/ } \\
\text { Caribbean, } \\
\mathrm{n}=30\end{array}$ & $\begin{array}{c}\text { North } \\
\text { America/ } \\
\text { Europe, } \\
\mathrm{n}=26\end{array}$ & $\begin{array}{c}\text { Other, } \dagger \\
n=26\end{array}$ & $\begin{array}{c}\text { Total, } \\
\mathrm{n}=722\end{array}$ \\
\hline \multicolumn{8}{|l|}{ Patient characteristics } \\
\hline \multicolumn{8}{|l|}{ Sex } \\
\hline M & $226(85)$ & $219(66)$ & $28(65)$ & $20(67)$ & $21(81)$ & $16(62)$ & $530(73)$ \\
\hline $\mathrm{F}$ & $41(15)$ & $111(34)$ & $15(35)$ & $10(33)$ & $5(19)$ & $10(38)$ & $192(27)$ \\
\hline Age, median (IQR) & $41(29-53)$ & $29(24-43)$ & $24(23-43)$ & $29(27-46)$ & $55(39-64)$ & $27(23-41)$ & $33(26-50)$ \\
\hline Age $\geq 60$ y & $37(14)$ & $27(8)$ & $4(9)$ & $3(10)$ & $8(31)$ & $4(15)$ & $83(11)$ \\
\hline \multicolumn{8}{|l|}{ Category of travelers } \\
\hline Tourism & $154(58)$ & $313(95)$ & $41(95)$ & $29(97)$ & $23(88)$ & $26(100)$ & $586(81)$ \\
\hline Business travelers & $93(35)$ & $17(5)$ & $2(5)$ & $1(3)$ & $3(12)$ & 0 & $116(16)$ \\
\hline Visiting friends or relatives & $19(7)$ & $1(<1)$ & 0 & 0 & 0 & 0 & $20(3)$ \\
\hline \multicolumn{8}{|l|}{ Type of illness } \\
\hline Potentially preventable & $85(32)$ & $25(8)$ & 0 & $1(3)$ & 0 & $1(4)$ & $112(16)$ \\
\hline \multicolumn{8}{|l|}{ Febrile conditions } \\
\hline \multicolumn{8}{|l|}{ Malaria } \\
\hline Plasmodium falciparum $\ddagger$ & $82(30)$ & $4(1)$ & 0 & 0 & 0 & 0 & $86(12)$ \\
\hline P. vivax & $23(9)$ & $7(2)$ & $3(7)$ & 0 & 0 & $3(12)$ & $36(5)$ \\
\hline$P$. ovale & $8(3)$ & 0 & 0 & 0 & 0 & 0 & $8(1)$ \\
\hline P. malariae & $7(3)$ & 0 & 0 & 0 & 0 & 0 & $7(<1)$ \\
\hline Unidentified malaria & $6(2)$ & $2(<1)$ & 0 & 0 & 0 & 0 & $8(1)$ \\
\hline Dengue fever & $4(1)$ & 59 (18) & $2(5)$ & $8(27)$ & 0 & $1(4)$ & $74(10)$ \\
\hline \multicolumn{8}{|l|}{ Enteric fever } \\
\hline Salmonella enterica serovar Typhi & $2(<1)$ & $19(6)$ & 0 & $1(3)$ & 0 & $1(4)$ & $23(3)$ \\
\hline S. enterica ser. Paratyphi & 0 & $36(11)$ & 0 & 0 & 0 & 0 & $36(5)$ \\
\hline Leptospirosis & $1(<1)$ & $18(5)$ & 0 & $7(23)$ & $1(4)$ & $2(8)$ & $29(4)$ \\
\hline Pneumonia & $10(4)$ & $11(3)$ & 0 & $1(3)$ & $5(19)$ & $1(4)$ & $28(4)$ \\
\hline Febrile diarrheal diseases & $10(4)$ & $5(2)$ & $1(2)$ & 0 & $2(8)$ & $1(4)$ & $19(3)$ \\
\hline Acute schistosomiasis & $16(6)$ & $3(<1)$ & 0 & 0 & 0 & 0 & $19(3)$ \\
\hline Influenza & 0 & $7(2)$ & 0 & 0 & 0 & $1(4)$ & $8(1)$ \\
\hline Epstein-Barr virus & $1(<1)$ & $6(2)$ & $1(2)$ & 0 & 0 & 0 & $8(1)$ \\
\hline Cytomegalovirus & $4(1)$ & $2(<1)$ & $2(5)$ & 0 & 0 & 0 & $8(1)$ \\
\hline Amebic liver abscess & 0 & $5(2)$ & 0 & 0 & 0 & $2(8)$ & $7(<1)$ \\
\hline Rickettsial diseases & $3(1)$ & $3(<1)$ & 0 & 0 & 0 & 0 & $6(<1)$ \\
\hline Upper respiratory tract infection & $4(1)$ & $1(<1)$ & 0 & 0 & 0 & 0 & $5(<1)$ \\
\hline Unspecified febrile illness & $34(13)$ & $55(17)$ & $7(16)$ & $3(10)$ & $6(23)$ & $4(15)$ & $109(15)$ \\
\hline Other febrile conditions & $15(6)$ & $29(9)$ & $8(19)$ & $2(7)$ & $3(12)$ & $2(8)$ & $59(8)$ \\
\hline \multicolumn{8}{|l|}{ Afebrile conditions } \\
\hline Afebrile diarrheal diseases & $5(2)$ & $7(2)$ & $2(5)$ & 0 & $4(15)$ & 0 & $18(2)$ \\
\hline Afebrile eosinophilia & $4(1)$ & $6(2)$ & $2(5)$ & $1(3)$ & $1(4)$ & $2(8)$ & $16(2)$ \\
\hline Skin disease & $7(3)$ & $4(1)$ & $2(5)$ & $1(3)$ & 0 & 0 & $14(2)$ \\
\hline Afebrile nondiarrheal GI illness & $3(1)$ & $8(2)$ & $2(5)$ & 0 & 0 & 0 & $13(2)$ \\
\hline Viral hepatitis & $2(<1)$ & $8(2)$ & 0 & $2(7)$ & 0 & 0 & $12(2)$ \\
\hline Leishmaniasis & $2(<1)$ & 0 & $9(21)$ & 0 & 0 & 0 & $11(2)$ \\
\hline Giardiasis & 0 & $4(1)$ & 0 & $1(3)$ & 0 & 0 & $5(<1)$ \\
\hline Other afebrile & $14(5)$ & $21(6)$ & $2(5)$ & $3(10)$ & $4(15)$ & $6(23)$ & $50(7)$ \\
\hline \multicolumn{8}{|l|}{ Outcome } \\
\hline Intensive care unit hospitalization & $4(1)$ & $4(1)$ & 0 & 0 & $2(8)$ & $1(4)$ & $11(2)$ \\
\hline Death & $1(<1)$ & $1(<1)$ & 0 & 0 & 0 & 0 & $2(<1)$ \\
\hline
\end{tabular}

vs. $1[3 \%]) ; p<0.01)$; male $(81[94 \%]$ vs. $26[72 \%]$; $\mathrm{p}<0.01)$; and to have traveled to middle and western Africa $(64[74 \%]$ vs. $0 ; \mathrm{p}<0.01)$. The annual number of $P$. vivax malaria hospitalizations declined during the study period from an average of 7.3 hospitalizations per year during 2004-2006 to $<1$ hospitalization per year during 2013-2015 $\left(\mathrm{R}^{2}=0.62\right)$.

Of the 181 acute life-threatening tropical diseases, $86(48 \%)$ were acquired in Africa and $83(46 \%)$ in
Asia (Table 2). Male sex, business travel, and travel to Africa characterized travelers hospitalized for treatment of life-threatening diseases. The most common causes of life-threatening illness requiring hospitalization were P. falciparum malaria (86 [48\%]) and enteric fever (59 [33\%]). Of the 74 cases of dengue fever, none were dengue hemorrhagic fever or dengue shock syndrome; therefore, no dengue cases were considered life-threatening. Eleven $(2 \%)$ hospitalized travelers required admission to 


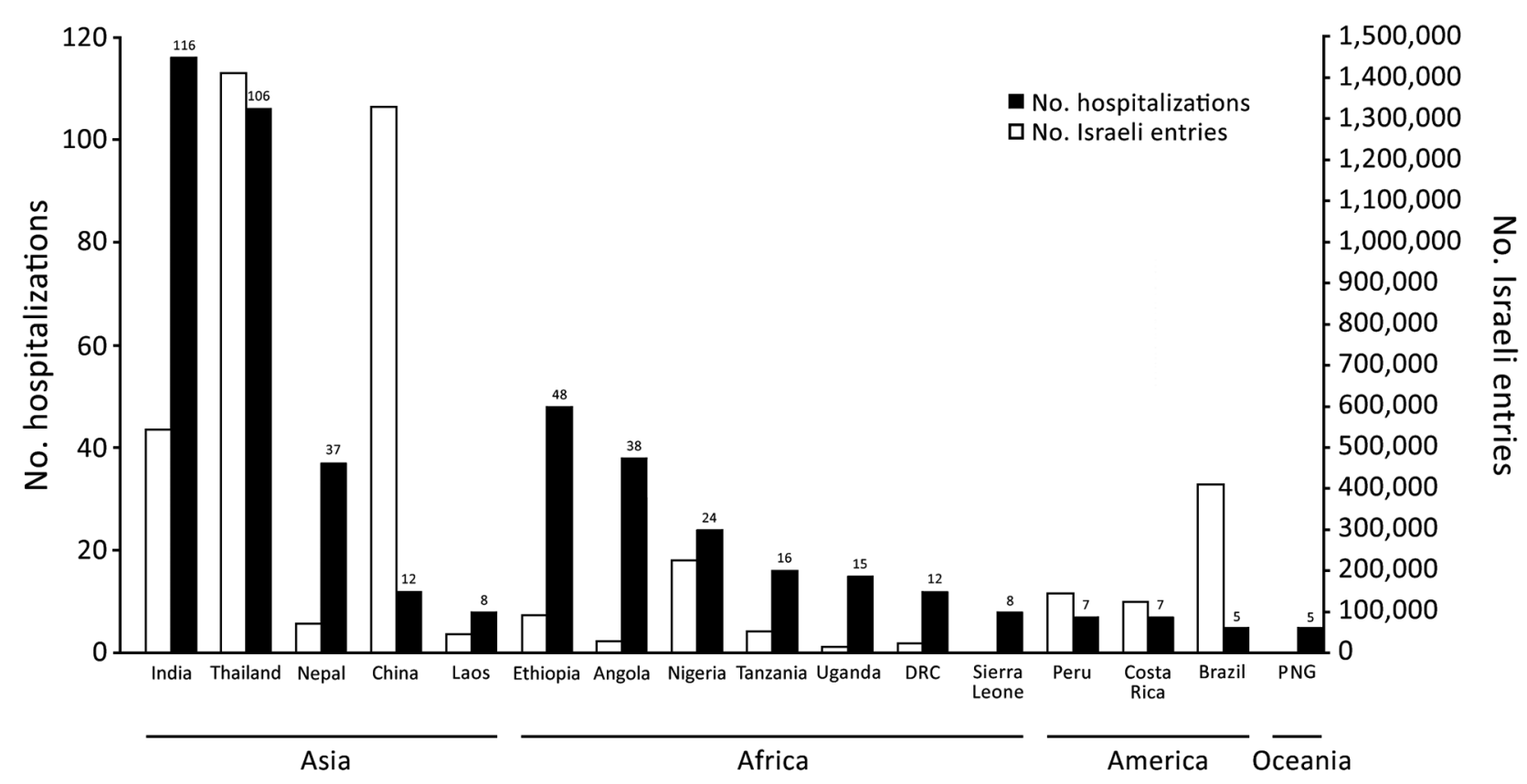

Figure. Travel-associated hospitalizations of citizens of Israel at Sheba Medical Center, Israel, by country of disease acquisition (A), and estimated number of Israeli citizen entries to each country (B), 2004-2005. Data on Israeli citizen entries from the United Nations World Tourism Organization (4). DRC, Democratic Republic of the Congo; PNG, Papua New Guinea.

an intensive care unit, and 2 of these patients died during their hospitalization. One patient died from endocarditis caused by Staphylococcus aureus and 1 from necrotizing fasciitis in a surgical wound while hospitalized for eosinophilia and abdominal mass.

A total of $112(16 \%)$ hospitalizations were potentially preventable by chemoprophylaxis or pretravel vaccination: P. falciparum malaria (86, 12\%); Salmonella enterica serovar Typhi $(23,3 \%)$; hepatitis A $(2,<1 \%)$; and acute hepatitis B $(1,<1 \%)$. Most of the life-threatening diseases acquired in Africa were potentially preventable (84, 98\%); significantly fewer $(25,30 \%)$ from Asia were potentially preventable $(\mathrm{p}<0.01)$.

\section{Conclusions}

We reviewed $>700$ posttravel hospitalizations of citizens in Israel during 2004-2015. Acute, life-threatening illnesses necessitated $25 \%$ of admissions, most of which were potentially preventable by malaria chemoprophylaxis or pretravel vaccination. Compared with other regions,

\begin{tabular}{|c|c|c|c|}
\hline Patient characteristics & Life-threatening illness, $\dagger \mathrm{n}=181$ & Non-life-threatening illness, $n=541$ & $p$ value \\
\hline Male sex & $145(81)$ & $385(71)$ & 0.02 \\
\hline Age, median (IQR) & $33(25-49)$ & $33(25-50)$ & 0.62 \\
\hline Elderly, age $\geq 60$ y & $15(8)$ & $68(13)$ & 0.12 \\
\hline \multicolumn{4}{|l|}{ Category of travelers } \\
\hline Tourism & $138(76)$ & $448(83)$ & 0.05 \\
\hline Business travelers & $43(24)$ & $73(13)$ & $<0.01$ \\
\hline Visiting friends or relatives & $0(0)$ & $20(3)$ & $<0.01$ \\
\hline \multicolumn{4}{|l|}{ Continent of travel } \\
\hline Africa & $86(48)$ & $181(33)$ & $<0.01$ \\
\hline Asia & $83(46)$ & $247(46)$ & 0.98 \\
\hline South America & 0 & $43(8)$ & $<0.01$ \\
\hline Central America and Caribbean & $8(4)$ & $22(4)$ & 0.83 \\
\hline North America and Europe & $1(<1)$ & $25(5)$ & $<0.01$ \\
\hline Other $\ddagger$ & $3(2)^{\prime}$ & $23(4)$ & 0.11 \\
\hline
\end{tabular}


nearly all life-threatening diseases in travelers returning from Africa were preventable.

Most travelers who were admitted to hospitals to treat preventable life-threatening diseases after returning from Africa were diagnosed with $P$. falciparum malaria. The number of $P$. vivax malaria hospitalizations declined during the study years, possibly related to discontinuation of rafting trips to the Omo River in Ethiopia, which had resulted a high number of infections in earlier years. In travelers returning from Asia, enteric fever was the second most common cause of hospitalization, after dengue fever; S. enterica ser. Paratyphi, for which an effective vaccine is not available, caused most of those illnesses. An outbreak of Salmonella Paratyphi A enteric fever in Nepal (5) may have contributed to this trend.

Our study has several limitations. SMC is the national referral center for travel-related illness; therefore, an unusually high number of severe or complicated illnesses may have affected our results. Because of the relatively small number of hospitalizations related to individual destination countries, singular events or large outbreaks may have biased the country-specific data (5). The Israeli traveler population is generally characterized by a low rate of travelers visiting friends and relatives, except travelers to Ethiopia. Approximately one third of the patients hospitalized after travel to Ethiopia were born in Ethiopia or born to parents from Ethiopia who immigrated to Israel. This relationship may have resulted in a higher posttravel hospitalization number among citizens of Israel returning from Ethiopia, because travelers visiting friends and relatives may be at a higher risk (6). Because of the different methods of traveler data capture used by different countries reporting to the United Nations World Tourism Organization, our use of the reported number of Israeli citizen entries from this dataset was limited to contextualize the number of hospitalizations from specific countries in relative terms, rather than to calculate country-specific rates of hospitalization.

In conclusion, Israeli citizens hospitalized to treat lifethreatening diseases after returning from travel to Africa were likely to suffer from preventable illnesses. Knowledge of region-specific hospitalization causes and impact should be used to identify at-risk travelers, enhance pretravel preparation, and advocate adherence to recommended vaccines and malaria prophylaxis.

\section{About the Author}

Dr. Avni is a medical intern at The Chaim Sheba Medical Center, Tel Hashomer, Israel. His research interests include infectious diseases, tropical diseases, travel medicine, and epidemiology.

\section{References}

1. Ryan ET, Wilson ME, Kain KC. Illness after international travel. N Engl J Med. 2002;347:505-16. http://dx.doi.org/10.1056/ NEJMra020118

2. Leder K, Torresi J, Libman MD, Cramer JP, Castelli F, Schlagenhauf P, et al.; GeoSentinel Surveillance Network. GeoSentinel surveillance of illness in returned travelers, 2007-2011. Ann Intern Med. 2013;158:456-68. http://dx.doi.org/ 10.7326/0003-4819-158-6-201303190-00005

3. Jensenius M, Han PV, Schlagenhauf P, Schwartz E, Parola P, Castelli F, et al.; GeoSentinel Surveillance Network. Acute and potentially life-threatening tropical diseases in western travelers - a GeoSentinel multicenter study, 1996-2011. Am J Trop Med Hyg. 2013;88:397-404. http://dx.doi.org/10.4269/ ajtmh.12-0551

4. United Nations World Tourism Organization. Israel: countryspecific: outbound tourism 1995-2016 (12.2017). Tourism statistics. 2017 [cited 2018 Mar 12]. http://www.e-unwto.org/doi/ abs/10.5555/unwtotfb0376250119952016201712

5. Meltzer E, Stienlauf S, Leshem E, Sidi Y, Schwartz E. A large outbreak of Salmonella paratyphi A infection among israeli travelers to Nepal. Clin Infect Dis. 2014;58:359-64. http://dx.doi.org/10.1093/cid/cit723

6. Ericsson CD, Hatz C, Leder K, Tong S, Weld L, Kain KC, et al. Illness in travelers visiting friends and relatives: a review of the GeoSentinel Surveillance Network. Clin Infect Dis. 2006;43:118593. http://dx.doi.org/10.1086/507893

Address for correspondence: Eli Schwartz, Center of Geographic Medicine, The Chaim Sheba Medical Center, Tel Hashomer 52621, Israel; email: elischwa@post.tau.ac.il; Eyal Leshem, Infectious Diseases Unit, The Chaim Sheba Medical Center, Tel Hashomer 52621, Israel; email: leshem@gmail.com 